Research Article

\title{
Development, properties and potential applications of high-energy fuel briquettes incorporating coal dust, biowastes and post-consumer plastics
}

\author{
Willis Gwenzi ${ }^{1}$ [D $\cdot$ Rumbidzai S. Ncube ${ }^{1} \cdot$ Tungamirai Rukuni $^{2}$
}

Received: 5 February 2020 / Accepted: 21 April 2020 / Published online: 3 May 2020

(c) Springer Nature Switzerland AG 2020

\begin{abstract}
The conversion of waste to energy through briquetting has the potential for providing energy, while simultaneously reducing wastes and their environmental health risks. The current study developed and evaluated high-energy fuel briquettes from mixtures of coal dust, biowastes and postconsumer plastics. Five waste mix ratios (wt\%) of coal dust (C), postconsumer plastics (P) and sawdust $(S)$ were tested: (1) C50-40-S10, (2) C-60-P30-S10, (3) C70-P20-S10, (4) C-80-P20-S0 and (5) C-80A-P0-S20. Waste mix ratio had a significant effect $(p<0.05)$ on water absorption, shatter index, compressive strength and energy values, but had no effect on density. The densities $\left(1.1-1.3 \mathrm{~g} / \mathrm{cm}^{3}\right)$ and shatter indices (94-98\%) of all briquettes conformed to international standard specifications for fuel briquettes, indicating that the briquettes had acceptable handling properties. A waste mixture ratio of $50 \%$ coal dust, $40 \%$ plastics and $10 \%$ sawdust (C50-P40-S10) produced a briquette with the best overall combination of handling and energy properties. The high-energy briquettes had calorific values of $26.5-33.8 \mathrm{MJ} / \mathrm{kg}$, which were significantly higher than or comparable to the maximum values reported for high-energy coal ( $27 \mathrm{MJ} / \mathrm{kg}$ ), while the compressive strength was $0.7 \mathrm{MPa}$. Potential applications of the briquettes include (1) household and institutional heating and cooking and (2) industrial heating in kilns, furnaces, smelters, curing and drying of crops (e.g., tobacco barns. Further work is required to address the following: (1) evaluation of the detailed physicochemical, combustion and emission properties, (2) optimization of the briquetting process, (3) cost estimation of the briquettes relative to existing competing solid fuels and (4) comparative performance evaluation of the briquettes versus conventional solid fuels in the various applications.
\end{abstract}

Keywords Calorific values · Energy balance analysis · Handling properties · Manual press system · Solid fuels · Waste-toenergy systems

We dedicate this paper to our late co-author and colleague Mr. Tungamirai Rukuni, who untimely passed away during the course of the research project.

Tungamirai Rukuni: Deceased.

$\triangle$ Willis Gwenzi, wgwenzi@yahoo.co.uk; wgwenzi@agric.uz.ac.zw | ${ }^{1}$ Biosystems and Environmental Engineering Research Group, Department of Soil Science and Agricultural Engineering, University of Zimbabwe, P.O. Box MP167, Mt. Pleasant, Harare, Zimbabwe. ${ }^{2}$ Development Technology Centre (DTC), Faculty of Agriculture, University of Zimbabwe, P.O. Box MP167, Mt. Pleasant, Harare, Zimbabwe. 


\section{Introduction}

Sub-Saharan Africa (SSA) experiences severe shortages of energy and relies on biomass fuels for household heating and cooking $[23,35]$. The over-reliance on biomass fuels partly accounts for the severe deforestation in SSA. Yet SSA generates large quantities of energy-rich biowastes and industrial and municipal solid wastes, posing significant human and environmental health risks $[17,29]$. In terms of biomass availability, in Zimbabwe alone, approximately one million tonnes of dry biomass were burnt in 2012, resulting in the production of 70 tonnes of nitrogen dioxide and 2700 tonnes of methane [46]. Here, we posit that waste-to-energy systems have the potential to address the energy and waste problems, which constitute a waste-energy nexus.

The conversion of waste to energy has recently attracted a lot of research attention in both developed and developing countries. Literature on waste-to-energy systems is dominated by studies on the pyrolysis and gasification of coal dust, plastics and biowastes as individual materials to produce liquid and gaseous fuels $[21,36]$. Although solid wastes may contain high chemical energy, their application as fuel sources is constrained by their loose nature, which implies low energy value per unit volume, high transport costs and poor handling properties [51]. Briquetting of waste materials into solid fuels has the potential to overcome these challenges and enable the use of wastes as precursor materials for the production of solid fuels [10]. Briquetting is a densification process in which pressure is applied to loose precursor materials with or without a binder to obtain a compact, durable and high-quality solid fuel [4]. Briquetting reduces the costs of handling, transportation and storage and increases the volumetric calorific values by increasing the bulk density and reducing moisture content $[26,44]$. The strength and energy properties of the briquettes depend on various factors, including (1) solid/binder ratio, (2) pressing pressure and time and (3) properties of the precursor materials $[4,6$, 51]. To date, some studies have investigated the development and evaluation of fuel briquettes using biomass [4, 20], but biomass briquettes tend to have low fixed carbon and low energy values [17]. A few studies have developed and evaluated briquettes from coal wastes $[10,41,51]$. However, limited data exist on the handling and energy properties of fuel briquettes incorporating various waste mixtures such as coal dust, biowastes and postconsumer plastics. Moreover, the capacity of low pressing pressures typical of manual presses and low-cost binders such as molasses to produce high-energy briquettes with acceptable handling properties from such complex waste mixtures remains poorly understood.
In SSA, waste-to-energy systems for decentralized energy provisions such as the production of fuel briquettes from wastes should fulfill the following preconditions: (1) use low-cost equipment such as manual presses that can be fabricated locally using readily available materials, (2) should be operated without electricity, which is in short supply and often unreliable, (3) should require minimum skills to operate and maintain, (4) the precursor waste materials should be readily available for free or at a low cost and (5) the energy value of the briquettes should be similar to or higher than that of conventional solid fuels such as charcoal, firewood or coal. In this regard, wasteto-energy systems that generate liquid and gaseous fuels via pyrolysis [40] that require complex reactor designs and control systems may not be ideal in SSA.

In the current study, we developed and evaluated the energy and handling properties of fuel briquettes incorporating various mixtures of coal dust, biowastes and postconsumer plastics using molasses as a binder. We hypothesized that (1) high-energy fuel briquettes with higher energy values than conventional solid fuels (e.g., firewood, coal) can be developed from waste mixtures using a manual press, and (2) the handling properties of the fuel briquettes will conform to engineering specification. The rationale for these hypotheses is that (1) solid wastes such as postconsumer plastics have higher calorific energy (e.g., 43.3-46.5 MJ/kg) than conventional solid fuels [49], and (2) briquetting of granular materials mixed with binders such as molasses has been reported to produce solid fuels with acceptable handling properties relative to precursor materials [51]. For example, coal dust and biowastes such as sawdust have energy values as high as $34 \mathrm{MJ} / \mathrm{kg}$ and $17.4 \mathrm{MJ} / \mathrm{kg}$, respectively [4, 24]. In addition, plastics easily undergo combustion as attested by anecdotal evidence showing their frequent use to start domestic fires in Africa. The objectives of the current study were: (1) to develop and fabricate high-energy fuel briquettes consisting of various waste mix ratios, (2) to evaluate the handling and calorific properties of the fuel briquettes relative to specifications and (3) to highlight the potential applications of the briquettes in waste-to-energy systems in sub-Saharan Africa.

\section{Materials and methods}

\subsection{Precursor waste materials}

The three precursor waste materials were: (1) coal dust (C), (2) postconsumer plastics $(P)$ in the form of polyethylene terephthalate (PET) bottles and (3) biowastes in the form of sawdust (S). Coal dust was obtained from a coal mining and processing plant in Hwange Colliery 
and was purchased from Harare Thermal Power Station in Harare, Zimbabwe. The coal is mined from the Karoo coal deposits located in Hwange area in the mid-Zambezi Basin, which hosts large coal reserves in Zimbabwe [39]. The coal from the Hwange which was used in the current study has the following characteristics [31, 33]: calorific value: $25.4-35.0 \mathrm{MJ} / \mathrm{kg}$, ash content: $54.7 \%$, fixed carbon: $23.5 \%$, low sulfur content: $0.99 \%$ and dry ash volatile matter: $26.3 \%$.

The PET plastics were obtained from PETRECOZIM, a private company that recycles PET bottles and other plastics. At PETRECOZIM, PET plastics are first washed using hot water, dried and then crushed into $144 \mathrm{~mm}^{2}$ flakes (average dimensions: $12 \mathrm{~mm} \times 12 \mathrm{~mm}$ ). Thereafter, the PET flakes are then washed in hot water $\left(90^{\circ} \mathrm{C}\right)$ to remove residual grit and dirt and then dried. Sawdust was obtained from a wood workshop at the University of Zimbabwe campus in Harare. All precursor materials were further dried for $24 \mathrm{~h}$ before use. Coal dust and sawdust were passed through a 2-mm sieve to remove large particles, while waste plastics were used as obtained.

\subsection{Overview of experimental work}

The experimental work was conducted following the sequential steps summarized in Fig. 1. Briefly, this involved: (1) determination of waste mix ratios, (2) fabrication of 24 briquette specimens and their subsequent preliminary evaluation to determine those with acceptable shatter indices, (3) fabrication of five briquette specimens with acceptable shatter indices and subsequent detailed evaluation of handling properties and (4) determination of the calorific/energy values of three briquette specimens with the best handling properties. Note that the number of briquettes was systematically reduced from 24 (step 2), to 5 (step 3 ) and then 3 (step 4) based on testing results at each stage. This approach was motivated by the fact that the detailed evaluation of a large number of specimens (i.e., 24 ) is cumbersome, time-consuming and costly. Thus, the systematic reduction of specimens at each step was meant to overcome this limitation, while achieving the desired high-energy briquettes.

\subsection{Preliminary determination of mix ratios}

A preliminary factorial experiment consisting of six waste mix ratios and four solid/binder ratios was conducted to determine the best combinations. The five preliminary waste mix ratios (wt\%) of coal dust (C), waste plastics $(\mathrm{P})$ and sawdust $(\mathrm{S})$ were tested: (1) C60-P30-S10, (2) C50-P40-S10, (3) C70-P20-S10, (4) C80-P20-S0 and (5) C80-P0-S20. These mix ratios were selected based on their theoretical energy values (Eq. 1). The four solid/ binder ratios investigated were $10 \%, 15 \%, 20 \%$ and $25 \%$

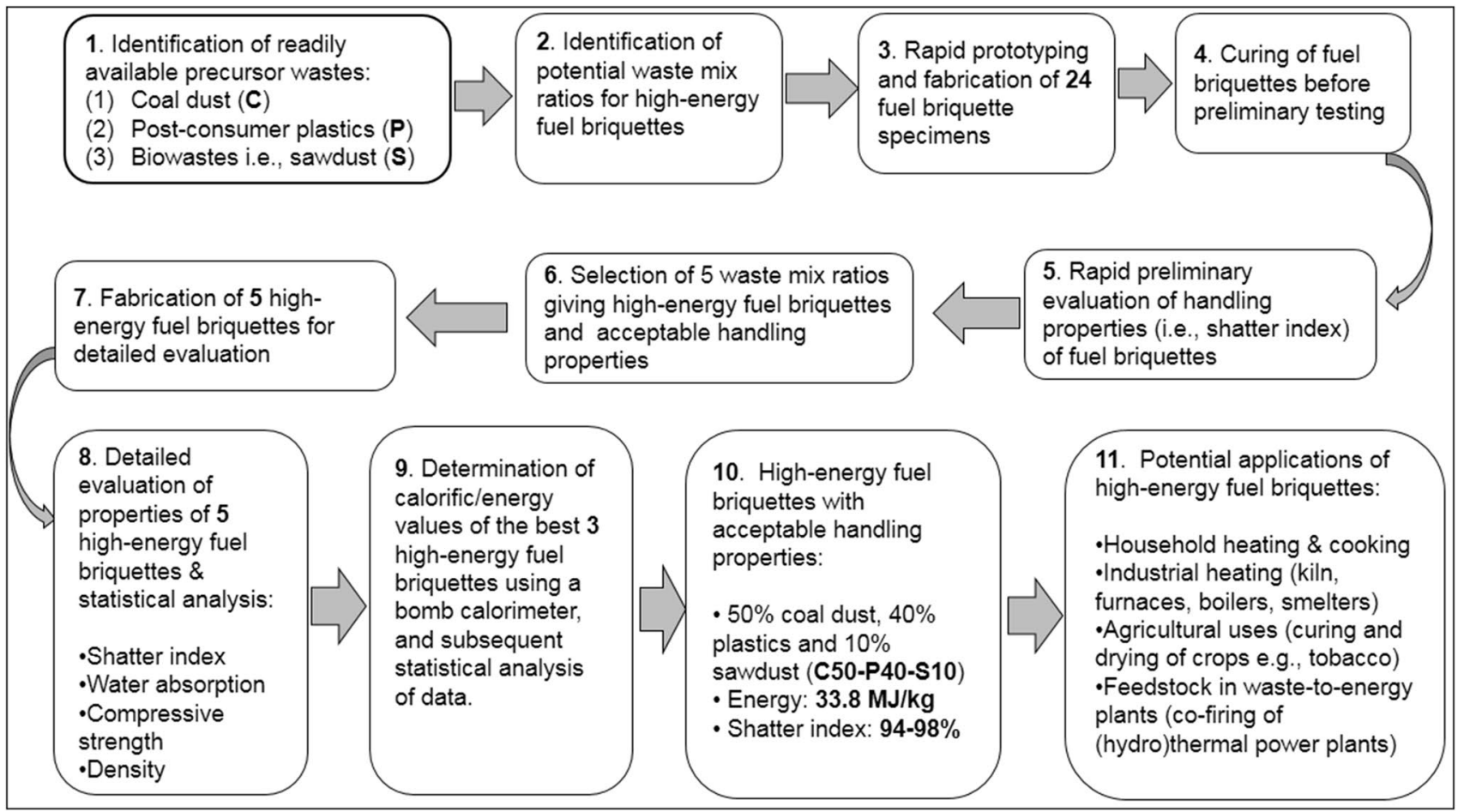

Fig. 1 A flow diagram highlighting the key sequential steps in the development and evaluation of high-energy fuel briquettes 
molasses. These mix ratios gave a total of 24 briquette specimens, each replicated three times to give a total of 72 specimens. Replicated (3) briquettes consisting of single-precursor waste materials were included as controls, giving an overall total of 81 briquettes.

The five waste mix ratios were determined to give fuel briquettes with theoretical energy values similar to or higher than that of conventional solid fuels (i.e., firewood, coal). To achieve this, the following energy values of the three precursor waste materials were obtained from the literature: (1) 25 to $35 \mathrm{MJ} / \mathrm{kg}$ for coal dust [31, 33], (2) 43.3 to $46.5 \mathrm{MJ} / \mathrm{kg}$ for waste plastics [49] and (3) $16.8-19 \mathrm{MJ} / \mathrm{kg}$ for sawdust [42]. The theoretical energy value of the resultant briquette was calculated as the sum of the product of the energy value and dry mass of waste in the briquette specimen (Eq. 1):

$E_{b}=\sum_{i=1}^{i=3} E_{i} \times W_{i}$

where $E_{\mathrm{b}}$ is the theoretical energy value of the resultant fuel briquette and $E_{\mathrm{i}}$ and $W_{\mathrm{i}}$ are the estimated energy values and proportion (wt \%) of each precursor waste material in the briquette, respectively.

\subsection{Fabrication and preliminary evaluation of briquettes}

The 81 briquette specimens were fabricated by mixing the appropriate waste mix ratios. The corresponding volume of molasses (binder) was then added to achieve the target solid/binder ratio. The solid/binder mixtures were then thoroughly mixed by hand. The briquette specimens were fabricated using a locally made manual press (Fig. 2). The manual press had a mold with internal dimensions that produced briquettes with a rectangular prism shape $(225 \mathrm{~mm}$ length $\times 105$ width $\times 65 \mathrm{~mm}$ thickness). For each briquette specimen, $2.5 \mathrm{~kg}$ of the waste mixture was placed in the mold, and ten blows were then applied using a manual press. The briquettes were then demolded from the mold and air-dried for seven days before preliminary testing.

During preliminary testing, only shatter index of the briquettes was measured as an indicator of handling and strength properties. Evaluation of shatter index of the 27 specimens yielded only five briquettes conforming to international standards for fuel briquettes (i.e., shatter index $\geq 90 \%$ ). All the five briquettes with acceptable shatter indices had a binder/solid ratio of $25 \%$. Table 1 presents the waste mix ratios of the five briquettes, which were subjected to detailed evaluation (Sect. 2.5).

\subsection{Detailed evaluation of briquette properties}

Shatter index, density, water absorption, compressive strength and energy values were determined to evaluate the strength, water resistance and energy properties of briquettes. The measurement procedures for each of the five parameters were destructive. Therefore, for each of the five briquette specimens, three replicates were fabricated for each of the five properties, giving a total of 75 briquettes. All tests were conducted using standard procedures described in the literature (i.e., British Standards (BS), ASTM). Handling and water absorption properties were determined in laboratories in the Departments of Civil Engineering, and Soil Science and Agricultural Engineering, while calorific values were determined at the Institute of Mining Research at the University of Zimbabwe campus in Harare.

\subsubsection{Strength properties}

The shatter index was determined using the drop test in accordance with BS 1016-108-108.1:1992 [11]. The initial mass of the briquette was measured, and the briquette was placed in a closed container. The container was then subjected to gravitational fall three times at a constant height of $2 \mathrm{~m}$. The contents of the container were passed through a 2.36-mm sieve, and the mass of the briquette retained on the sieve was recorded. The shatter index was calculated as follows (Eq. 2):

$K=\frac{B_{z}}{B} \times 100$

where $K$ is the shatter index (\%), $B_{z}$ is the mass of the briquette retained $(\mathrm{kg})$ and $B$ is the initial mass of the briquette $(\mathrm{kg})$.

The compressive strength values were determined according to BS EN 12390-3:2009 [14] using a compression testing machine equipped with a digital reader at a load rate of $0.05 \mathrm{~N} / \mathrm{mm}^{2} / \mathrm{s}$. Compressive strength (CS) was calculated according to Eq. (3):

$S=\frac{F}{A}$

where CS is the compressive strength ( $\mathrm{MPa}), F$ is the maximum compressive force applied $(\mathrm{kN})$ at the point of briquette failure and $A$ is the surface area of the briquette $\left(\mathrm{m}^{2}\right)$.

Density $\left(\rho, \mathrm{kg} \mathrm{m}^{-3}\right)$ was determined according to ASTM-D2395 as the ratio of the mass $(M, \mathrm{~kg})$ to the 
Fig. 2 Precursor waste materials (a), manual press (b), fabricated high-energy fuel briquettes (c) and their surface and internal morphological characteristics of briquettes (d and e)

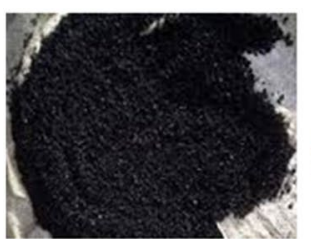

Coal dust (C)

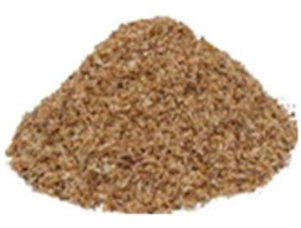

Biowastes i.e., Sawdust (S)

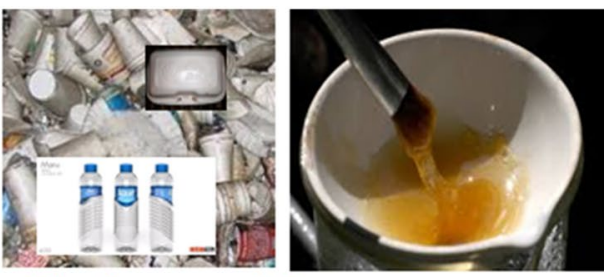

Plastic wastes (P)

(a) Precursor materials

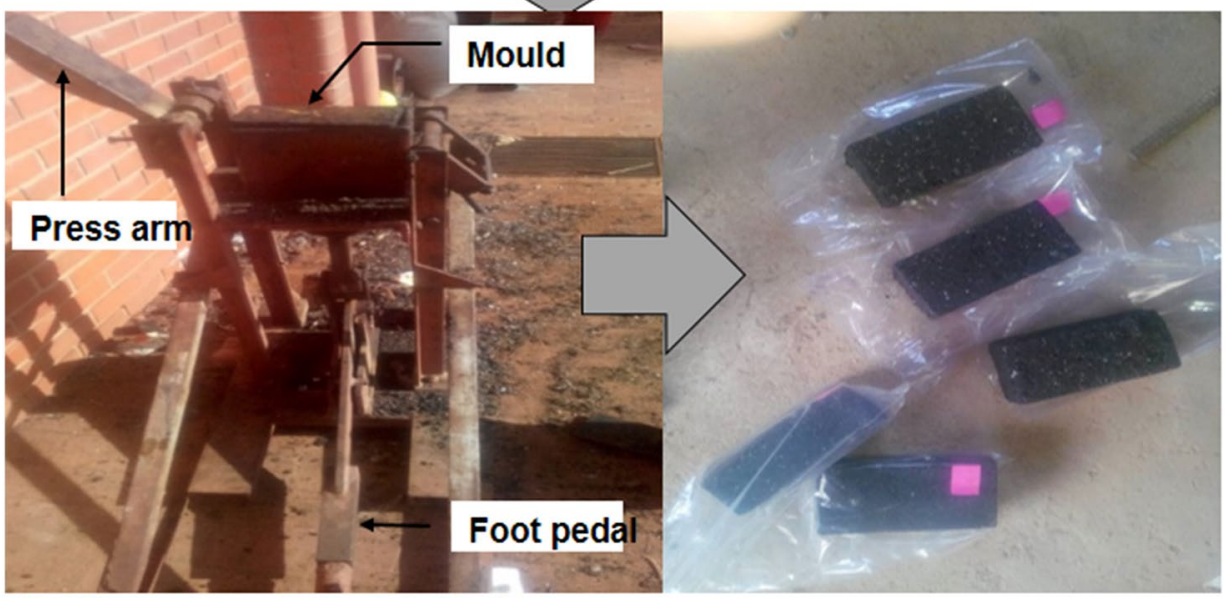

(b) Manual press for fabrication

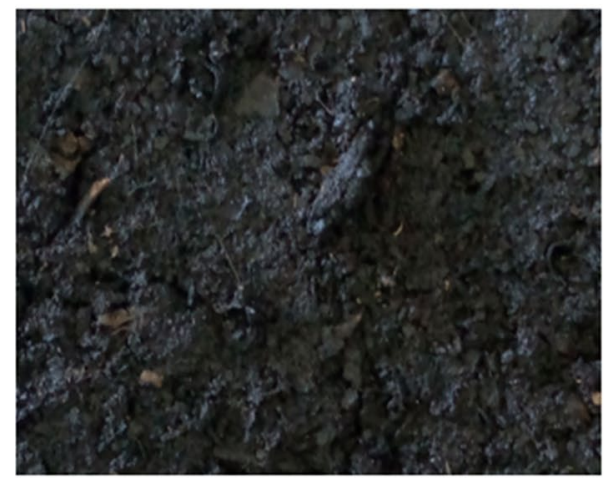

(d) Surface morphology (c) High-energy briquettes

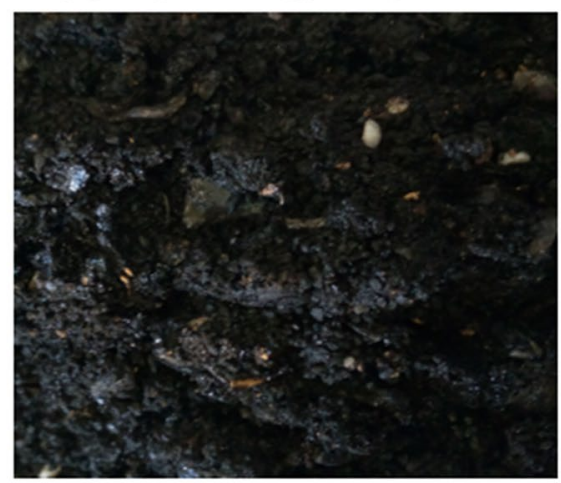

(e) Internal morphology
Table 1 Waste mix ratios (wt\%) of fuel briquette specimens conforming to standard specification for shatter index. All specimens had a binder/ solid ratio of $25 \%$ (wt)

\begin{tabular}{llllll}
\hline$\#$ & Coal dust (C) & $\begin{array}{l}\text { Plastic waste } \\
(\mathrm{P})\end{array}$ & Sawdust (S) & C-P-S mix ratio & Briquette acronym \\
\hline 1 & 60 & 30 & 10 & $1: 6: 3$ & C60-P30-S10 \\
2 & 50 & 40 & 10 & $1: 5: 4$ & C50-P40-S10 \\
3 & 70 & 20 & 10 & $1: 7: 2$ & C70-P20-S10 \\
4 & 80 & 20 & 0 & $0: 8: 2$ & C80-P20-S0 \\
5 & 80 & 0 & 20 & $2: 8: 0$ & C80-P0-S20 \\
\hline
\end{tabular}

corresponding volume $\left(V, \mathrm{~m}^{3}\right)$ of briquette specimens (Eq. 4): 
$\rho=\frac{M}{V}$

\subsubsection{Water resistance properties}

Water absorption was measured according to BS EN 1352325:2014 [13] to evaluate the resistance to water/humidity during storage and transportation. The initial dimensions of the briquettes were measured. The briquettes were then immersed in water for $10 \mathrm{~min}$, and their dimensions were measured thereafter. The water absorption $(R)$ was calculated as ratio of the change in dimensions after immersion to the initial dimensions (Eq. 5):

$R=\frac{\Delta x}{x} \times 100$

where $R$ is the water absorption (\%), $\Delta x$ is the change in dimensions after water immersion $(\mathrm{m})$ and $x$ is the initial dimensions before immersion $(\mathrm{m})$.

Based on the water absorption results, two briquettes (C60-P30-S10 and C80-P0-S20) were discarded because they had water absorption exceeding the maximum acceptable value of $30 \%$. Thus, only three briquettes, namely C50-P40-S10, C70-P20-S10 and C80-P20-S0, were taken to the next stage for the determination of calorific values (Sect. 2.4.3).

\subsubsection{Energy/calorific values}

The energy values were determined for three briquettes (C50-P40-S10, C70-P20-S10 and C80-P20-S0) using a digital bomb calorimeter (IKA C5000) in accordance with BS 7420:1991 [12]. Briefly, a known mass (1 g) of the briquette was placed into a crucible and placed in the bomb calorimeter, and then ignited. A known volume of distilled water was then poured into the base of the bomb which was charged with oxygen to $2500 \mathrm{kPa}$. The energy values were directly read from the digital calorimeter.

\subsubsection{Indicative energy balance analysis for briquettes}

In the current study, the energy required to produce the briquettes was not directly quantified. Energy requirement for briquetting is a critical parameter, but this aspect was inadvertently overlooked; hence, this was beyond the scope of the current study. Lacking experimental data, indicative energy requirements were estimated based on the literature [42]. Therefore, based on published data for the drying and crushing (plastics) of precursor materials and subsequent briquetting, an indicative energy balance analysis for the briquettes was conducted. Specifically, the following estimated energy requirements were used: (1) $2.25 \mathrm{MJ} / \mathrm{kg}$ for drying of each precursor material, (2) $0.41 \mathrm{MJ} / \mathrm{kg}$ for crushing waste plastics and (3) 0.04 to $0.10 \mathrm{MJ} / \mathrm{kg}$ for briquetting [42]. For each briquette, the energy value for each process was adjusted accordingly to account for the proportion (wt\%) of each precursor waste material. Using data on total energy used, and the energy values of the briquettes, the following ratios were estimated: (1) energy used to energy gained, and (2) net energy gained to total energy consumed. These ratios are proxy indicators of whether converting the waste mixtures into briquettes results in overall negative or positive energy balance.

\subsection{Data analysis}

The experimental design and subsequent data analysis used in the current study were based on univariate statistics. First, the Kolmogorov-Smirnov and Levene tests were used to evaluate the normality and homogeneity of data on briquette properties, respectively. Then, data obeying these two assumptions were subjected to a oneway analysis of variance (ANOVA) to determine the effects of waste mix ratios on the properties of briquettes. Data that violated the ANOVA assumptions were either transformed to attain normality and homogeneity of variance or analyzed using the nonparametric Kruskal-Wallis test. The least significant difference (LSD) was used to separate means in cases where significant differences were observed. A one-sample $t$ test was used to compare the observed mean data on briquette properties to standard specifications and values in the literature for conventional solid fuels such as coal, charcoal and firewood. All data analyses were done using SPSS version 16 at a probability level $(p)$ of 0.05 . All summary data on briquette properties are presented as the average \pm the standard error of the mean of three replicates.

\section{Results}

\subsection{Prototypes of fuel briquettes}

Figure $2 c$, d, e shows specimens of the high-energy fuel briquettes developed for detailed evaluation. The briquettes had a rectangular prism shape and showed no evidence of deformation or cracks even after curing. The cured briquettes were dense and easy to handle, with no evidence of flaking or disintegration during handling. These observations generally indicate that the manual press and waste mix ratios investigated in the current study can be used to produce briquettes with acceptable handling properties. These visual observations were consistent with the results of strength properties (Sect. 3.2). 


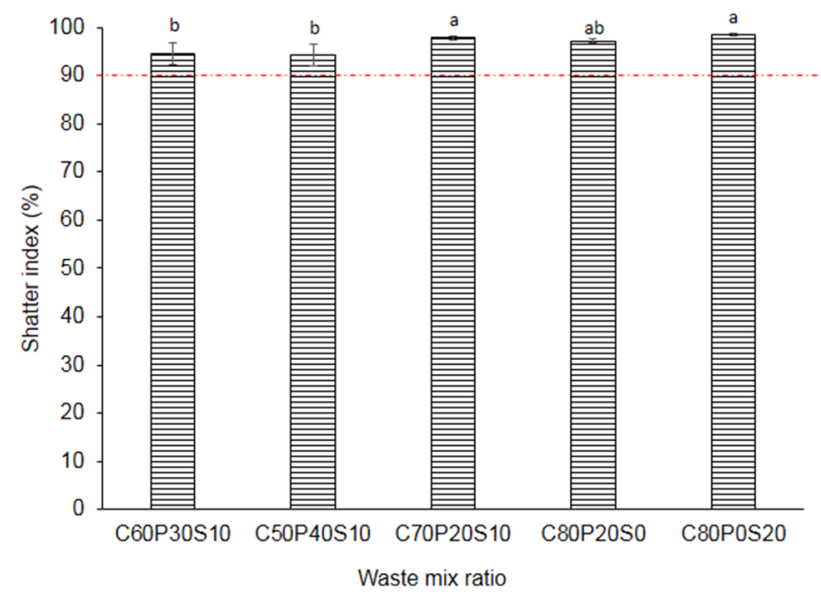

Fig. 3 Effect of different mix ratios (wt\%) of coal dust (C), waste plastics $(P)$ and sawdust $(S)$ on shatter index of fuel briquettes. In all figures, data shown are mean \pm the standard errors of the means of three replicates, while different letters indicate significant differences at a probability level $p=0.05$. The minimum shatter index for fuel briquettes according to British standard is shown by horizontal line

\subsection{Strength properties of briquettes}

Shatter index varied significantly $(p=0.002)$ among the briquettes containing the various waste mix ratios (Fig. 3); $70 \%$ coal dust, $20 \%$ plastics and $10 \%$ sawdust (C70-P20-S10) and $80 \%$ coal dust, $0 \%$ plastics and $20 \%$ sawdust (C80-P0-S20) gave briquettes with significantly higher shatter indices than those containing $60 \%$ coal dust, $30 \%$ plastics and $10 \%$ sawdust (C60-P30-S10) and $50 \%$ coal dust, $40 \%$ plastics and $10 \%$ sawdust (C50-P40-S10). However, all briquettes had shatter indices above the minimum acceptable value of $90 \%$ [10].

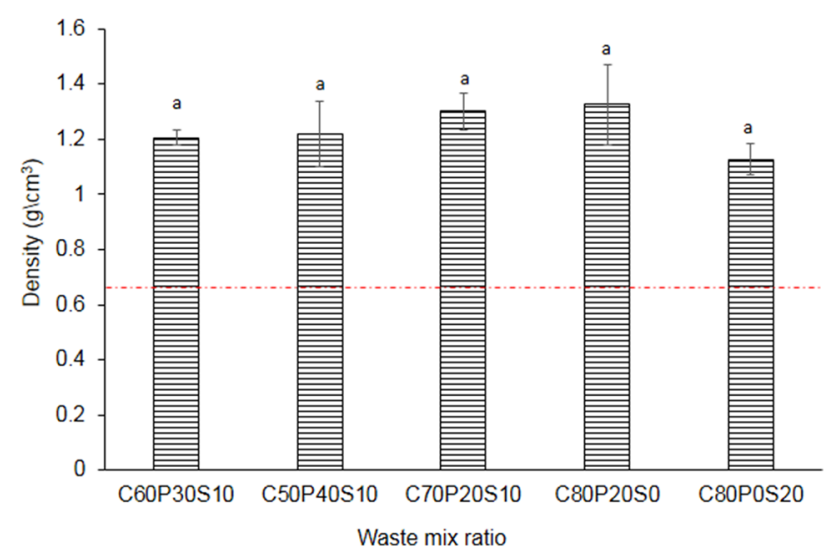

Fig. 4 Effect of different mix ratios (wt\%) of coal dust (C), waste plastics $(P)$ and sawdust $(S)$ on density of fuel briquettes. The minimum density for fuel briquettes according to British standard is shown by horizontal line
The densities of the briquettes were statistically similar $(p=0.071)$ among the various waste mix ratios (Fig. 4). All briquettes had high densities $\left(1.1-1.3 \mathrm{~g} / \mathrm{cm}^{3}\right)$, which were about two times higher than minimum acceptable value of $0.6 \mathrm{~g} / \mathrm{cm}^{3}$ [54]. This indicates the manual press provided adequate compressive stress to increase the density of the loose precursor materials.

The waste mix ratios had a significant effect $(p<0.001)$ on the compressive strength of briquettes (Fig. 5). The compressive strength significantly decreased in the order: C80-P20-S0 followed by C50-P40-S10 and C70-P20-S10, then C60-P30-S10 and lastly, C80-P0-S20. The compressive strength values were marginal compared to the ideal value of 1.0 MPa for high-quality fuel briquettes [10]. Comparison of Figs. 3 and 4 versus Fig. 5 shows that the effects of waste mix ratios on compressive strength were more pronounced than on density and shatter index.

\subsection{Water absorption properties}

Waste mix ratios had a pronounced and significant effect $(p<0.001)$ on water absorption properties of briquettes (Fig. 6a). Three briquettes (C50-P40-S10, C70-P20-S10 and (80-P20-S0) had acceptable water absorption values $(<30 \%)$ [4]. The water absorption of the three briquettes significantly decreased in the order: $\mathrm{C} 50-\mathrm{P} 40-\mathrm{S} 10$, then C70-P20-S10 and lastly C80-P20-S0. The remaining two briquettes (C80-P0-S20 and C60-P30-S10) had significantly higher water absorption than the other three briquettes. Moreover, the water absorption values for these two briquettes exceeded the maximum acceptable values for fuel briquettes. Figure $6 \mathrm{~b}$ shows a significant inverse linear relationships between water absorption (WA) and compressive strength (CS) (WA $=-74.2 \times C S+70.6$; $\left.r^{2}=0.84, p<0.001\right)$. This indicates that briquettes with low

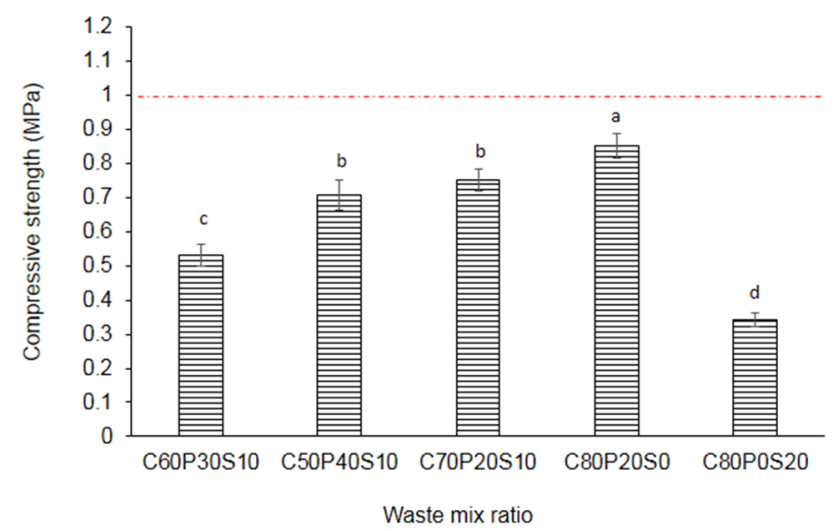

Fig. 5 Effect of different mix ratios (wt\%) of coal dust (C), waste plastics $(\mathrm{P})$ and sawdust $(\mathrm{S})$ on compressive strength of fuel briquettes. The minimum compressive strength for fuel briquettes according to British standard is shown by horizontal line 

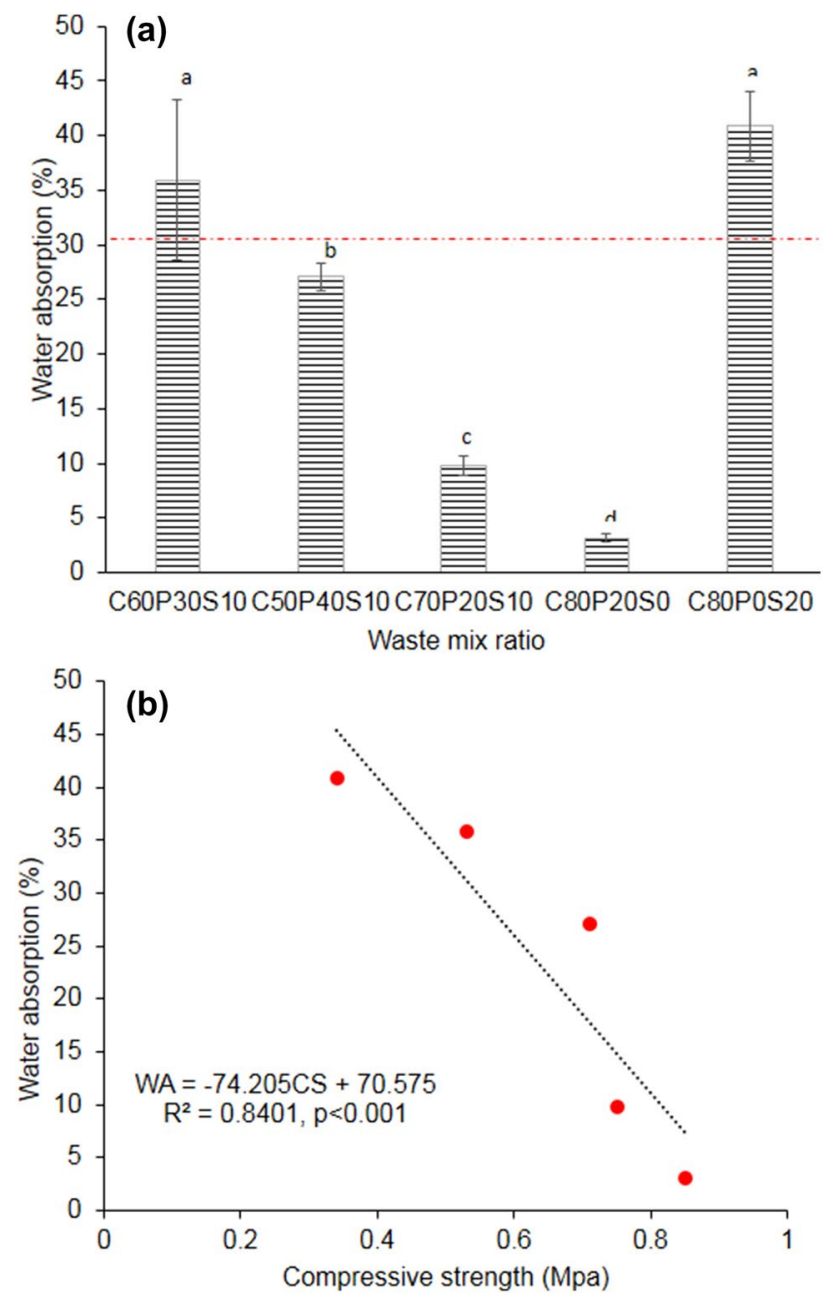

Fig. 6 (a) Effect of different mix ratios (wt\%) of coal dust (C), waste plastics (P) and sawdust (S) on water absorption of fuel briquettes. The maximum water absorption for fuel briquettes according to British standard is shown by horizontal line. (b) Inverse linear relationship between water absorption and compressive strength

compressive strength absorbed more moisture than those with higher compressive strength values.

\subsection{Energy values of briquettes}

Waste mix ratios had a significant effect $(p=0.041)$ on the energy value of the briquettes (Fig. 7). A briquette consisting of $50 \%$ coal dust, $40 \%$ waste plastics and $10 \%$ sawdust (C50-P40-S10) had significantly higher energy values than the other two briquettes. The energy values of C70-P20-S10 (26.5 MJ/kg) and C80-P20-S0 (27.9 MJ/ $\mathrm{kg}$ ) were approximately two times higher than those of low-energy coal $(\sim 15 \mathrm{MJ} / \mathrm{kg})$, but similar to that of highenergy coal $(27.9 \mathrm{MJ} / \mathrm{kg})$. The energy value $(33.8 \mathrm{MJ} / \mathrm{kg})$ of the best briquette (C50-P40-S10) was significantly higher than that of high-energy coal. In terms of energy value,

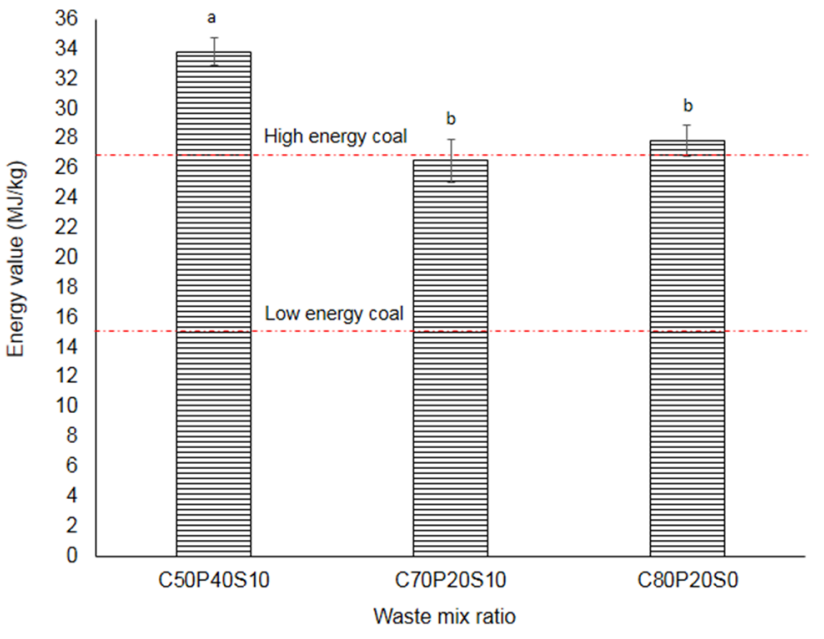

Fig. 7 Effect of different mix ratios (wt \%) of coal dust (C), waste plastics $(P)$ and sawdust $(S)$ on the energy values of fuel briquettes. The average maximum and minimum energy values of coal are shown by the horizontal lines

water absorption and strength properties, C50-P40-S10 was the best overall briquette.

\subsection{Indicative energy balance analysis for briquettes}

Based on the estimated energy used for drying (2.25 MJ/ $\mathrm{kg})$, crushing of plastics $(0.41 \mathrm{MJ} / \mathrm{kg})$ and briquetting $(0.04-0.10 \mathrm{MJ} / \mathrm{kg})$, the total energy consumed ranged from 2.29 to $2.51 \mathrm{MJ} / \mathrm{kg}$ (Table 2). C50-P40-S10 had the highest total energy, followed by C70-P20-S10 and then C80-P20-S0. As expected, higher total energy used for briquetting $\mathrm{C} 50-\mathrm{P} 40-\mathrm{S} 10$ than the other briquettes was attributed to the energy required for crushing a relatively high proportion of plastics (40\%). The total energy for the production of briquettes accounted for just $7-9 \%$ of the energy value of the briquettes $(26.5-33.8 \mathrm{MJ} / \mathrm{kg})$, giving net energy gained of 24.07 to $31.35 \mathrm{MJ} / \mathrm{kg}$ (Table 2). Thus, the conversion of the waste mixtures to high-energy fuel briquettes increased the net energy gained by factors of 9.9 to 12.7. Overall, the briquettes have a positive net energy balance, equivalent to approximately one order of magnitude relative to total energy used (Table 2).

\section{Discussion}

\subsection{Development and fabrication of briquettes}

The development of fuel briquettes from nonconventional precursor materials could be cumbersome and time-consuming due to the need to develop and evaluate a large 
Table 2 Indicative energy balance analysis for the high-energy fuel briquettes

\begin{tabular}{llllll}
\hline Briquette & $\begin{array}{l}\text { Total energy used (drying, } \\
\text { crushing and briquetting) } \\
\mathrm{kg})\end{array}$ & $\begin{array}{l}\text { Energy value of } \\
\text { briquettes }(\mathrm{MJ} / \mathrm{kg})\end{array}$ & $\begin{array}{l}\text { Net energy } \\
\text { gained }(\mathrm{MJ} / \mathrm{kg})\end{array}$ & $\begin{array}{l}\text { Ratio of energy used to } \\
\text { energy value of briquettes } \\
(\%)\end{array}$ & $\begin{array}{l}\text { Ratio of energy } \\
\text { gained to energy } \\
\text { used }(-)\end{array}$ \\
\hline C50-P40-S10 & $2.45-2.51$ & 33.8 & $31.29-31.35$ & $7.3-7.4$ & $12.5-12.7$ \\
C80-P20-S0 & $2.29-2.35$ & 27.9 & $25.55-25.61$ & $8.2-8.4$ & $10.9-11.2$ \\
C70-P20-S10 & $2.37-2.43$ & 26.5 & $24.07-24.13$ & $9.0-9.2$ & $9.9-10.1$ \\
\hline
\end{tabular}

number of briquette specimens with various waste mix ratios (i.e., a total of 81 in this case). To overcome this drawback, a sequential protocol was developed for the rapid determination of appropriate waste mix ratios of coal dust, biowastes and waste plastics, giving briquettes with high energy values and adequate handling properties. In this protocol, briquettes failing a given criterion at each stage were disregarded in subsequent steps. This generic protocol was considered ideal for developing regions such as SSA, because it enables rapid prototyping and saves resources, time and effort.

The use of readily and freely available waste materials and a locally made manual press was motivated by the need to demonstrate the feasibility to develop highenergy fuel briquettes using locally available resources. The manual press used in the current study can be fabricated from scrap metal, and its estimated cost is approximately US\$50. Manual hand presses similar to the one used in this study attain compressive pressures of approximately $0.05-4 \mathrm{~N} / \mathrm{mm}^{2}[1,34]$ compared to $15 \mathrm{~N} / \mathrm{mm}^{2}$ for automated press systems [8]. The use of a manual press was motivated by the fact that some of the target end users of the technology in SSA (i.e., households, cooperatives, small-scale enterprises) often lack access to electricity, which is often expensive and unreliable. This is in contrast to automated press systems, which are relatively more expensive, require electricity and are more sophisticated to design and fabricate; thus, they are not readily available in SSA.

\subsection{Strength properties of briquettes}

The shatter index indicates the percentage of fuel retained on a sieve of a given aperture (i.e., $2.36 \mathrm{~mm}$ in this case) after subjecting the briquettes to a drop test. The shatter indices for all the briquettes were high and above the recommended $90 \%$ (Fig. 3), indicating that the briquettes retained their form $[9,10]$. The shatter index values observed in the current study are similar to those reported for briquettes made from biomass $[4,30]$ and coal fines [33]. The shatter index values were consistent with the high density observed for the briquettes (Fig. 4). The observed high density values $\left(1.1-1.3 \mathrm{~g} / \mathrm{cm}^{3}\right)$ were more than three times higher than those reported by Lubwama and Yiga [30] for biomass briquettes made from groundnut shells $\left(0.259 \mathrm{~g} / \mathrm{m}^{3}\right)$ and bagasse $\left(0.183 \mathrm{~g} / \mathrm{m}^{3}\right)$. The high density values show that the waste mixtures, molasses binder and pressing conditions applied in the current study effectively densified the waste mixtures. The high density values indicate that the briquettes are highly resistant to mechanical irregularities [4].

Despite the high densities, the compressive strength values of the briquettes were moderate and below the 1.0 MPa often recommended for high-quality fuel briquettes (Fig. 5). Compressive strength indicates the resistance of the briquettes to failure when subjected to compressive forces. Although lower than the standard values for high-quality briquettes, the compressive strength is adequate to ensure that the briquettes remain intact even when subjected to moderate compressive forces during transportation and storage. The reason for the relatively low compressive strength are unclear. One would have expected that the incorporation of plastics could reduce the compressive strength given the plastic behavior of such materials, and the putative poor particle-to-particle contact induced by plastic flakes. However, comparison of the compressive strength of the briquette with no plastics (i.e., $0.34 \mathrm{MPa}$ for C80-P0-S20) to those with 20-40\% plastics (i.e., $0.71 \mathrm{MPa}$ for $\mathrm{C} 50-\mathrm{P} 40-\mathrm{S} 10$ ) does not support this notion (Fig. 5). Therefore, the compressive strength could reflect the complex interactions among properties and proportion of the precursor materials, particle-particle interactions, bonding mechanisms and compression process. The mechanisms accounting for the development of strength during briquetting are highly complex and include (1) increasing particle-to-particle interactions such as particle interlocking and (2) formation of bridgetype bonds between solid particles and molasses [4, 30, 48]. Overall, the results indicate that the briquettes had adequate strength to enable handling, packaging, storage and transportation without significant failure.

\subsection{Water absorption}

Three briquettes (C50-P40-S10, C70-P20-S10 and C80-P20-S0) out of the five had acceptable water 
absorption values (Fig. 6a). The water absorption is indicative of the capacity of briquettes to withstand water or high humidity, including swelling during transport and storage [4]. Two briquettes (C80-P0-S20 and C60-P30-S10) had water absorption above $30 \%$; thus, they are likely to undergo deterioration, including swelling and deformation when exposed to water or high humidity during transport and storage. However, in some studies, briquettes with water absorption values of less than $50 \%$ per minute have been considered as acceptable [16]. A significant inverse linear relationship was observed between water absorption and compressive strength (Fig. 6b). This relationship suggests that the water absorption capacity of the briquettes can be reduced by increasing the compressive strength via increasing the compressive force or pressing time.

In briquetting, high water absorption is often associated with inherent binders such as lignin in lignocellulosic biomasses and externally applied water-soluble organic binders such as molasses [4]. Therefore, the two briquettes (i.e., C80-P0-S20 and C60-P30-S10) with high water absorption capacities should be stored in dry conditions under cover or sheds to avoid deterioration. Besides deterioration during storage, high water absorption influences the combustion properties and heating values of briquettes, especially during gasification. For example, water vapor in gasification processes creates saturated conditions at high temperatures, which may cause briquettes to rapidly disintegrate [4]. In turn, this may reduce the overall efficiency of the system via two mechanisms: (1) the lose materials may exit the reactor or boiler in unburnt form, and (2) the materials may block the airflow into the reactor and interfere with the gasification process.

\subsection{Energy values of briquettes}

The energy values of all the three briquettes were significantly higher than or similar to that of conventional solid fuels such as firewood, charcoal and coal (Fig. 7; Table 3). The energy values were also higher than those reported in the literature for biochars [47]. Biochars are formed through the pyrolysis of biomass, a process almost similar to that used for the production of charcoal. Table 3 presents a comparison of the energy values of the briquettes developed in the current study to conventional solid fuels and other briquettes reported in the literature.

Table 3 Summary of energy values of the briquettes developed in the current study to those in the literature

\begin{tabular}{|c|c|c|}
\hline Solid fuel & Energy values (MJ/kg) & Remarks and references \\
\hline \multicolumn{3}{|l|}{ A: Current briquettes } \\
\hline C50-P40-S10 & 33.8 & Energy value significantly higher than high-energy coals \\
\hline C80-P20-S0 & 27.9 & Energy values similar to high-energy coals \\
\hline C70-P20-S10 & 26.5 & Energy values similar to high-energy coals \\
\hline \multicolumn{3}{|l|}{ B: Conventional } \\
\hline Dry wood & $14.4-17.4$ & $\begin{array}{l}\text { High heating values reported based on gross calorific values [24]. Values may } \\
\text { vary between softwoods and hardwoods }\end{array}$ \\
\hline \multicolumn{3}{|l|}{ Coal products } \\
\hline $\begin{array}{l}\text { (i) Anthracite } \\
\text { (ii) Coke } \\
\text { (iii) Bituminous coal } \\
\text { (iv) Lignite }\end{array}$ & $\begin{array}{l}32.5-34 \\
28-31 \\
17.0-23.3 \\
16.3\end{array}$ & $\begin{array}{l}\text { High heating values reported based on gross calorific values. Values may vary } \\
\text { depending on moisture and ash content [24] }\end{array}$ \\
\hline Charcoal & 28-33 & Values reported are for high-quality charcoal [3] \\
\hline \multicolumn{3}{|l|}{ C: Briquettes } \\
\hline Coal briquettes & $25-26$ & Briquettes made from coal fines and sawdust using molasses as a binder [33] \\
\hline Biomass briquettes & $\begin{array}{l}21-23 \text { (carbonized feedstock) } \\
16 \text { (non-carbonized feedstock) }\end{array}$ & $\begin{array}{l}\text { Briquettes were developed from groundnut shells and bagasse using cassava } \\
\text { and wheat starch binders [30] }\end{array}$ \\
\hline Biomass briquettes & 25.6 & Briquettes were made from charcoal from sugar-cane bagasse fly ash [45] \\
\hline Biomass briquettes & 18.6 & Briquettes made from sawdust mixed with burnt engine oil [43] \\
\hline Biomass briquettes/pellets & $\begin{array}{l}15.0-15.7 \text { (pellets) } \\
17.0-17.8 \text { (briquettes) }\end{array}$ & Briquettes and pellets were made from maize straw [28] \\
\hline Biomass briquettes & $15.1-18.7$ & $\begin{array}{l}\text { Briquettes were made in Nairobi, Kenya from biowastes, including charcoal } \\
\text { dust, waste paper, maize cob dust and sawdust [37] }\end{array}$ \\
\hline Biomass briquettes & $10-15$ & Average values reported for various biomasses [47] \\
\hline Biomass briquettes & $16.2-19.1$ & $\begin{array}{l}\text { Data are high heating values (HHV) for solid fuel developed from urban leaf } \\
\text { litter [38] }\end{array}$ \\
\hline
\end{tabular}


In summary, the energy values of the current briquettes were superior compared to briquettes reported in the literature. Wood, including sawdust, has relatively low energy values (16.8-19 MJ/kg) compared to coal dust and waste plastics [42]. Thus, the high energy values of the current briquettes could be attributed to the high energy values of the coal and waste plastics. The coal dust used in the current study was derived from highquality coal in Zimbabwe, with energy values ranging from 25 to $35 \mathrm{MJ} / \mathrm{kg}[31,33]$. In addition, plastics have been reported to have high energy values of approximately $43.3-46.5 \mathrm{MJ} / \mathrm{kg}$, although actual values may vary among plastic types [49]. The high energy values make the briquettes ideal for various applications. Overall, the findings support the original hypothesis that highenergy fuel briquettes with acceptable strength, water absorption and energy properties can be developed by using the appropriate mixtures of the three energy-rich precursor waste materials.

\subsection{Indicative energy balance analysis}

The net energy gained by briquetting waste mixtures exceeded the energy used for the production process by an order of magnitude, resulting in positive overall energy balances (Table 2). The ratios of energy used to energy gained in the current study (7.0-9.0\%) were two times lower than the values reported for biomass briquettes (12.13-17.64\%) [42]. The positive energy balances were attributed to the high energy values of the briquettes developed in the current study (Table 3), which were approximately two times those for biomass briquettes $[37,42]$. Note that the assumed energy required for the drying of coal ash and sawdust (2.25 MJ/kg) was based on data for wet biomass with a target reduction in moisture content of approximately from 60 to $15 \%[19,42]$. Therefore, the actual energy values for drying both coal dust and sawdust are expected to be lower than those for wet biomass. Therefore, in reality, it is likely that the energy required for drying, and by inference, the total energy for the production of the briquettes could be lower than the values reported here. In addition, one study even indicates that the energy required for compression and extrusion of briquettes using a hydraulic system can be as low as $12-30 \mathrm{MJ} /$ ton, equivalent to $0.12-0.30 \mathrm{MJ} / \mathrm{kg}$ [32]. Thus, using such hydraulic systems, scope exists to reduce the total energy used, and consequently, increase the ratio of energy gained to energy used. In summary, in terms of energetics, these indicative positive energy balances point to the feasibility of briquetting coal dust, plastics and biowastes into a high-energy solid fuel for potential applications in waste-to-energy systems.

\subsection{Potential applications of briquettes in sub-Saharan Africa}

In summary, the superiority of the current briquettes includes (1) high energy values comparable to or even higher than conventional nonrenewable solid fuels such as coal, charcoal and firewood (Table 3) and (2) the putative better handling properties than the precursor granular materials (i.e., sawdust, coal dust, postconsumer plastics). In addition, briquetting solid wastes provides a potential solid fuel, while simultaneously reducing the health risks associated with current disposal practices for such solid wastes.

In sub-Saharan Africa (SSA), the bulk of the population lack access to the electricity grid system; thus, they rely on biomass fuels, contributing to deforestation [37]. In this regard, the high energy values of the briquettes coupled with adequate handling properties make them ideal alternatives to conventional biomass fuels such as firewood and charcoal. The high-energy briquettes can be used for household heating and cooking, either on their own, or as an integral part of an energy mix including conventional biomass fuels. At household level, the briquettes could be used in traditional 'three-stone' cookstoves commonly used in SSA, and even in pyrolytic or biochar cookstoves $[22,25]$. Pyrolytic/biochar cookstoves are more energy efficient and release less toxic emissions than traditional three-stone cookstoves [22, 25]. The briquettes can also be used to provide energy for institutional heating and cooking in rural schools and clinics, which often depend on biomass fuels for heating and cooking.

The high-energy briquettes can also be used for industrial heating systems. In SSA, high fuel demand for drying and curing of crops such as tea, coffee and tobacco has been associated with rampant deforestation in countries such as Zimbabwe. Moreover, the industrial production of fired earth bricks and cement and metallurgical processes such as smelting are energy-intensive processes that require large quantities of firewood, coal or electricity. Therefore, the briquettes can also be used to fire industrial boilers, kilns, furnaces, smelters and tobacco curing barns, where coal and firewood are currently the predominant sources of energy. Examples of such industrial applications include steel production, pottery/ceramic kilns and cement manufacturing plants [50]. In waste-to-energy power plants, the briquettes can also be used as an alternative to coal and biomass for firing or co-firing of thermal power plants. Water-to-energy systems using briquettes as an energy source are likely to have lower environmental footprints than thermal power plants using conventional fuels such as coal and biomass. This is because the briquettes use industrial wastes as precursor materials, rather than pristine raw materials such as coal and biomass. 
The conversion of energy-rich industrial wastes to fuel briquettes for household, institutional and industrial applications is potentially attractive in SSA for various reasons. These reasons may also determine the initial uptake and subsequent adoption and even the sustainability of the briquetting technology. In summary, the reasons are as follows:

1. Besides their high energy, briquettes have several other potential advantages, including the simplicity of the production process using a low-cost manual press, which make them an ideal waste-to-energy technology for developing regions such as SSA.

2. Acute energy shortages, dwindling firewood sources and lack of access to highly centralized electricity grids create ideal conditions for alternative fuel sources such as briquettes. This is particularly true in informal settlements in slums, urban and peri-urban areas in SSA.

3. The waste feedstocks for briquetting are readily and freely available in SSA. For example, large coal reserves and coal mining operations exist in several SSA countries (e.g., in Zimbabwe, South Africa, Mozambique, among others), which generate enormous quantities of coal dust, currently lying idle in stockpiles. As Gwenzi et al., [23] and Duku et al. [18] indicated in the case of Zimbabwe and Ghana, respectively, large quantities of municipal solid wastes including postconsumer plastics are generated annually. Moreover, most countries in SSA have agro-based economies, which generate large quantities of biowastes from agro-processing. These wastes are currently disposed of in nonengineered waste dumps or burnt, thereby posing human and environmental health risks. Thus, the briquetting technology provides a potential winwin solution for addressing the waste-energy nexus in SSA.

4. Potential to create small enterprises and employment based on the briquette value chains, particularly among the youths in urban and peri-urban areas as reported in Kenya [37]. This is particularly important in SSA given the high unemployment rates driven by rapid population growth, low levels of industrialization and economic development.

\subsection{Future research}

The current study was limited to the development and fabrication of briquettes, and subsequent evaluation based on univariate statistics. Understandably, a number of knowledge gaps need to be addressed before the full potential of the briquetting technology is realized. These knowledge gaps include:
1. The need for detailed physicochemical analysis, including chemical composition and ash properties,

2. The current study relied on univariate statistics (i.e., one-way ANOVA) to determine the waste mix ratios that give the briquettes with best combination of energy and handling properties. Therefore, systematic optimization of the production process is required using prominent optimization tools in product development such as response surface methodology [27]. Such future research should investigate the effects of various production conditions, including waste mix ratios, pressing times and pressures, solid-adhesive ratios and their combination.

3. Investigating the use of heated plastic as a binder, a process that will require strict automated temperature control to allow plastics to form a liquid phase without generating volatiles. Such a hot briquetting technology may enable the development of a continuous industrial-scale briquette production process.

4. Comparative studies are required to evaluate the performance, including combustion characteristics and energy efficiencies of the high-energy briquettes versus conventional solid fuels in the various potential applications highlighted in the current study.

5. Development of a business model, including market analysis and detailed cost-benefit analysis of the briquettes relative to existing competing solid fuels such as coal, charcoal and firewood.

6. Detailed life cycle assessment of the environmental footprints of the briquettes, including greenhouse gases and toxic emissions relative to conventional solid fuels.

7. Comprehensive assessment of the technical, financial and socioeconomic feasibility to determine sustainability of the technology under various scenarios.

\section{Conclusions and Outlook}

The current proof-of-concept study showed that the calorific values of the high-energy briquettes were significantly higher than or similar to the maximum values reported for conventional solid fuels such as firewood, charcoal and coal. The density, water adsorption and shatter index of the briquettes conformed to international standard specifications for fuel briquettes. The briquette specimen containing a waste mixture of $50 \%$ coal dust, $40 \%$ plastics and $10 \%$ sawdust (C50-P40-S10) had the best overall handling and energy properties. Comparison of the energy values and energetics of the current highenergy briquettes to values reported in the literature for other briquettes further showed the superiority of the current briquettes. These findings demonstrate that the 
high-energy briquettes with acceptable strength and handing properties can be developed from a mixture of coal dust, postconsumer plastics and biowastes using a simple manual press. Potential uses of the high-energy briquettes include household and institutional heating and cooking, industrial heating, curing and drying in agroprocessing, and as feedstock in water-to-energy thermal power plants. Given that the current briquettes were fabricated using a manual press, which offered limited options to vary the operating conditions (e.g., pressing pressure), scope exists to further improve and optimize the properties by developing and using an automatic press system. The fuel briquette technology is particularly ideal for countries in sub-Saharan Africa, including Zimbabwe for four reasons: (1) the existence of coal reserves and coal mining and processing operations generating coal dust, which is the main precursor material for the briquettes, (2) predominantly agro-based economies, generating readily available biowastes and biomass, (3) large quantities of postconsumer plastics from the packaging industries and (4) acute shortages of energy, coupled with severe environmental pollution from poor solid waste management practices. Thus, the fuel briquette technology could be a scalable and environmentally friendly win-win solution to the waste-energy nexus in sub-Saharan Africa, with potential to simultaneously creating value chain and employment opportunities. However, the evaluation of the briquette was limited to strength, water resistance and energy properties. Therefore, further work is required on the following: (1) the detailed physicochemical analysis, including chemical composition and ash properties, (2) combustion characteristics and analysis of environmental footprints, including quantifying toxic emissions and greenhouse gases, (3) optimization of the briquetting process and (4) development of a business model, including market analysis and detailed cost-benefit analysis of the briquettes relative to existing competing solid fuels such as coal and firewood.

\begin{abstract}
Acknowledgements The work received no external funding; hence, this was solely funded by the authors. However, the analytical costs for the determination of calorific value of the briquettes were partly met by a biochar research project funded by the Swedish International Foundation for Science (IFS) Grant Number C/5266-2 awarded to WG, to which we are very grateful. Coal dust used in the current study was purchased from Harare Thermal Power Station, and no special permission was required to use it for research purposes. Postconsumer plastics in the form of crushed polyethylene terephthalate (PET) were kindly provided by PETRECOZIM and used with their permission. We thank the two anonymous reviewers for their comments that greatly improved the manuscript. Authors are solely responsible for research design, implementation and decision to publish the manuscript
\end{abstract}

Authors' contributions WG originated the idea, conceptualized the research, and compiled, finalized and revised the manuscript; RSN designed experiment and collected experimental data as part of her BSc honors thesis under the supervision of WG and TR. All authors contributed to experimental design, data analysis and interpretation.

\section{Compliance with ethical standards}

Conflict of interest All authors declare no conflict of interest.

\section{References}

1. Adam EA, Agib ARA (2001) Compressed stabilised earth block manufacture in Sudan, United Nations Educational Scientific and Cultural Organization. https://unesdoc.unesco.org/image s/0012/001282/128236e.pdf. Accessed 15 Dec 2019

2. Altun NE, Hicyilmaz C, Bagci AS (2003) Combustion characteristics of coal briquettes. 1. Thermal features. Energy Fuels 17(5):1266-1276

3. Antal MJ Jr, Grønli M (2003) The art, science, and technology of charcoal production. Ind Eng Chem Res 2003(42):1619-1640

4. Antwi-Boasiako C, Acheampong BB (2016) Strength properties and calorific values of sawdust-briquettes as wood-residue energy generation source from tropical hardwoods of different densities. Biomass Bioenerg 85:144-152. https://doi. org/10.1016/j.biombioe.2015.12.006

5. ASTM (American Standards for Testing and Materials) D2395$14 \mathrm{e} 1$ Standard test methods for density and specific gravity (relative density) of wood and wood-based materials. ASTM.

6. Blesa MJ, Fierro V, Miranda JL, Moliner R, Palacios JM (2001) Effect of the pyrolysis process on the physicochemical and mechanical properties of smokeless fuel briquettes. Fuel Process Technol 74(1):1-17

7. Blesa MJ, Miranda JL, Moliner R, Izquierdo MT, Palacios JM (2003) Low-temperature co-pyrolysis of a low-rank coal and biomass to prepare smokeless fuel briquettes. J Anal Appl Pyrol 70(2):665-677

8. Booysen Q (2009) Automatic block making machine. U.S. Patent Application 12/280, 160. Hydraform Developments Pty Ltd

9. Borowski G (2007) The possibility of utilizing coal briquettes with a biomass. Environ Prot Eng 33(2):79

10. Borowski G, Hycnar JJ (2013) Utilization of fine coal waste as a fuel briquettes. Int J Coal Prep Util 33(4):194-204

11. BS (British Standards) (1992) BS 1016-108-108.1:1992, Methods for analysis and testing of coal and coke. Tests special to coke. Determination of shatter indices. British Standards.

12. BS (British Standards) (1991) BS 7420:1991, Guide for determination of calorific values of solid, liquid and gaseous fuels (including definitions). British Standards.

13. BS (British Standards) (2014) BS EN 13523-25:2014, Coil coated metals. Test methods. Resistance to humidity. British Standards.

14. BS (British Standards) (2009) BS EN 12390-3:2009, Testing hardened concrete. Compressive strength of test specimens. British Standards.

15. Chiemchaisri C, Charnnok B, Visvanathan C (2010) Recovery of plastic wastes from dumpsite as refuse-derived fuel and its utilization in small gasification system. Biores Technol 101(5):1522-1527

16. CRAG (Centre de Recherches Agronomiques de I'Etat Gembloux) (1987) Briquetting agricultural and wood residues: Experience gained with a heated dye cylindrical screw press (English). In: J Carre, J Hebert, L Lacrosse, Y Schenkel (eds) Handling and processing of biomass for energy. Report and Proceedings; CNRE Bulletin (FAO), Centre de Recherches Agronomiques, Gembloux (Belgium), pp 45-52 (18). 
17. Demirbaş A (2005) Fuel and combustion properties of bio-wastes. Energy Sources 27(5):451-462

18. Duku MH, Gu S, Hagan EB (2011) Biochar production potential in Ghana-a review. Renew Sustain Energy Rev 15(8):3539-3551

19. Fagernäs L, Brammer J, Wilén C, Lauer M, Verhoeff F (2010) Drying of biomass for second generation synfuel production. Biomass Bioenergy 34:1267-1277

20. Felfli FF, Rocha JD, Filippetto D, Luengo CA, Pippo WA (2011) Biomass briquetting and its perspectives in Brazil. Biomass Bioenerg 35(1):236-242

21. Ferrara F, Orsini A, Plaisant A, Pettinau A (2014) Pyrolysis of coal, biomass and their blends: performance assessment by thermogravimetric analysis. Bioresour Technol 171:433-441

22. Gwenzi W (2018) Biochar cookstoves as a potential clean energy source for household heating and cooking in developing countries. In: Kalderis D, Ntarlagiannis D, Soupios P (eds) Non-soil biochar applications. Nova Science Publishers, Hauppauge

23. Gwenzi W, Chaukura N, Mukome FN, Machado S, Nyamasoka B (2015) Biochar production and applications in sub-Saharan Africa: opportunities, constraints, risks and uncertainties. J Environ Manag 150:250-261

24. IMTE AG (2005) Higher calorific values for some common fuels a coke, oil, wood, hydrogen and many more (unpublished data)

25. Jetter J, Zhao Y, Smith KR, Khan B, Yelverton T, DeCarlo P, Hays MD (2012) Pollutant emissions and energy efficiency under controlled conditions for household biomass cookstoves and implications for metrics useful in setting international test standards. Environ Sci Technol 46(19):10827-10834

26. Kaliyan N, Morey RV (2009) Factors affecting strength and durability of densified biomass products. Biomass Bioenerg 33(3):337-359

27. Khuri Al, Mukhopadhyay S (2010) Response surface methodology. Wiley Interdiscip Rev Comput Stat 2(2):128-149

28. Krizan M, Kristof K, Angelovic M, Jobbagy J, Urbanovicova O (2018) Energy potential of densified biomass from maize straw in form of pellets and briquettes. Agron Res 16(2):474-482. https://doi. org/10.15159/AR.18.074

29. Kumar PS, Sankaranarayanan G (2016) Investigation on environmental factors of waste plastics into oil and its emulsion to control the emission in DI diesel engine. Ecotoxicol Environ Saf 134(2):440-444. https://doi.org/10.1016/j.ecoenv.2016.01.021

30. Lubwama M, Yiga VA (2017) Development of groundnut shells and bagasse briquettes as sustainable fuel sources for domestic cooking applications in Uganda. Renew Energy 111:532-542. https:// doi.org/10.1016/j.renene.2017.04.041

31. Makomo Resources (2019) Thermal power products: Makomo coal thermal power Station Products Spreadsheet 2018. Makomo Resources (Pvt) Ltd. https://makomoresources.com/coal-produ cts/. Accessed 12 July 2019.

32. Mani S, Tabil LG, Sokhansanj $S$ (2006) Specific energy requirement for compacting corn stover. Bioresour Technol 97:1420-1426. https://doi.org/10.1016/j.biortech.2005.06.019

33. Manyuchi MM, Mbohwa C, Muzenda E (2018) Value addition of coal fines and sawdust to briquettes using molasses as a binder. $S$ Afr J Chem Eng 26:70-73

34. Masuka S, Gwenzi W, Rukuni T (2018) Development, engineering properties and potential applications of unfired earth bricks reinforced by coal fly ash, lime and wood aggregates. J Build Eng 18:312-320. https://doi.org/10.1016/j.jobe.2018.03.010

35. Mwampamba TH (2007) Has the woodfuel crisis returned? Urban charcoal consumption in Tanzania and its implications to present and future forest availability. Energy Policy 35:4221-4234. https:// doi.org/10.1016/j.enpol.2007.02.010

36. Melendi-Espina S et al (2015) Coal and plastic waste co-pyrolysis by thermal analysis-mass spectrometry. Fuel Process Technol 137:351-358

SN Applied Sciences

A SPRINGER NATURE journal
37. Njenga MM, Karanja NK, Gathuru K, John M, Munyao P, Mwasi B, Awika H, Mugwanja A, Muthoni M (2008) Enhancing livelihoods of the urban youth through recycling of organic waste for energy briquette making at Kahawa Soweto informal settlement. Nairobi, World Agroforestry Cente, Nairobi

38. Nurmatov N, Gomez DAL, Hensgen F, Bühle L, Wachendorf $M$ (2016) High-quality solid fuel production from leaf litter of urban street trees. Sustainability 8:1249. https://doi.org/10.3390/su812 1249

39. Oesterlen PM, Lepper J (2005) The Lower Karoo coal (k2-3) of the Mid-Zambezi basin, Zimbabwe: depositional analysis, coal genesis and palaeogeographic implications. Int J Coal Geol 61:97-118

40. Panda AK, Singh RK, Mishra DK (2010) Thermolysis of waste plastics to liquid fuel: a suitable method for plastic waste management and manufacture of value added products-a world prospective. Renew Sustain Energy Rev 14(1):233-248

41. Ryemshak SA et al (2015) Production of smokeless briquetted fuel by co-carbonization of local coals and bitumen. Int J New Technol Res 1(8):58-63

42. Sakkampang C, Tanakorn WT (2014) Study of ratio of energy consumption and gained energy during briquetting process for glycerin-biomass briquette fuel. Fuel 115:186-189

43. Singh RN, Bhoi PR, Patel SR (2007) Modification of commercial briquetting machine to produce $35 \mathrm{~mm}$ diameter briquettes suitable for gasification and combustion. Renew Energy 32:474-479. https ://doi.org/10.1016/j.renene.2006.02.001

44. Tabares JLM, Granada E, Moran J, Porteiro J, Murillo S, Gonzalez LML (2006) Combustion behaviour of Spanish lignocellulosic briquettes. Energy Sources A Recovery Util Environ Effects 28(6):501-515

45. Teixeira SR, Pena AFV, Miguel AG (2010) Briquetting of charcoal from sugar-cane bagasse fly ash (scbfa) as an alternative fuel. Waste Manag 30:804-807. https://doi.org/10.1016/j.wasma n.2010.01.018

46. Tubiello FN, Salvatore M, Ferrara AF, House J, Federici S, Rossi $S$, Biancalani R, Condor Golec RD, Jacobs H, Flammini A, Prosperi $P$ (2015) The contribution of agriculture, forestry and other land use activities to global warming, 1990-2012. Glob Change Biol 21(7):2655-2660

47. Verma M, Godbout S, Brar SK, Solomatnikova O, Lemay SP, Larouche JP (2012) Biofuels production from biomass by thermochemical conversion technologies. Int J Chem Eng 8:1-6

48. Venter P, Naude N (2015) Evaluation of some optimum moisture and binder conditions for coal fines briquetting. J S Afr Inst Min Metall 115:329-333

49. Williams $E$, Williams $P$ (1997) The pyrolysis of individual plastics and plastic mixture in a fixed bed reactor. J Chem Technol Biotechnol 70(1):9-20

50. World Coal Institute (2005) The coal resource: a comprehensive overview of coal the coal resource. World Coal Institute, London, pp 1-44

51. Yaman S, Kuc S (2001) Fuel briquettes from biomass-lignite blends. Fuel Process Technol 72:1-8

52. Yaman S, Sahan M, Haykiri-acma H, Sesen K, Kucukbayrak S (2000) Production of fuel briquettes from olive refuse and paper mill waste. Fuel Process Technol 68:23-31

53. Yang LH, Zhang X, Liu S (2009) Underground coal gasification using oxygen and steam. Energy Sources A Recovery Util Environ Effects 31(20):1883-1892

54. Zhang J, Guo Y (2014) Physical properties of solid fuel briquettes made from Caragana korshinskii Kom. Powder Technol 256:293-299

Publisher's Note Springer Nature remains neutral with regard to jurisdictional claims in published maps and institutional affiliations. 